\title{
ANALISIS KETEPATAN KODE NEOPLASMA DI RUMAH SAKIT ISLAM SULTAN AGUNG SEMARANG
}

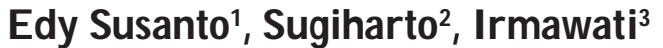 \\ 1,2,3] urusan R ekam M edis dan Informasi K esehatan Poltekkes K emenkes Semarang \\ J I. Tirto Agung, Pedalangan , Banyumanik, Semarang

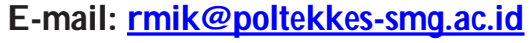

\begin{abstract}
The type of study is quantitative descriptive with cross sectional study. The population of this study are neoplasm patients in September-Desember 2015 about 429 patients, with the sample are 81 documents. The samplecollected by Simple RandomSampling technique. In this study, data collected by observation and noted with check list. Data analyzed by description and served using table. The result showed that the number of neoplasm cases at Sultan Agung Hospital of Semarang in February and March in 2016 are 414 patient. The accuracy of neoplasmcodeat Sultan Agung Hospital of Semarang is 0\% accurateand $100 \%$ inaccurate for morphological code. Then the neoplasm code is $48 \%$ accurate and $52 \%$ inaccurate.
\end{abstract}

Keywords: Accuracy, NeoplasmCode, ICD 10

\begin{abstract}
Abstrak
J enis penelitian ini adal ah deskriptif kuantitatif dengan menggunakan pendekatan cross sectional. Populasi dal am penelitian ini adal ah kasus neoplasma pasien rawat inap pada bulan September-Desember tahun 2015 sebanyak 429 kasus, dengan sampel yang di dapat sejumlah 81 dokumen. Pengambilan sampel menggunakan Teknik Simple RandomSampling. Pengumpulan data dalam penelitian ini menggunakan metode observasi dan dicatat menggunakan check list. Data dianal isis secara deskriptif dan di sajikan menggunakan tabel. Hasil penelitian menunjukkan bahwajumlah kasus neoplasma di RSI Sul tan Agung Semarang pada bulan Februari dan Maret Tahun 2016 adal ah sebanyak 414 pasien. Tingkat Ketepatan kodeneoplasma di RSI SultanAgung Semarang $0 \%$ kode akurat dan $100 \%$ kode tidak akurat untuk kode morfologi. Kemudian untuk kode site sebesar $48 \%$ kode akurat dan $52 \%$ kode tidak akurat.
\end{abstract}

K ata K unci: Ketepatan, Kode Neoplasma, ICD 10

\section{PENDAHUL UAN}

Berdasarkan Undang-undang Nomor 44 Tahun 2009, rumah sakit adal ah institusi pel ayanan kesehatan yang menyelenggarakan pelayanan kesehatan perorangan secara paripurna yang menyediakan pelayanan rawat inap, rawatjalan, dan gawat darurat Dalammendukung penyelenggaraan kesehatan yang baik dan bermutu, rumah sakit perlu menyelenggarakan rekam medis. Rekam medis adalah berkas yang berisikan catatan dan dokumen tentang identitas pasien, pemeriksaan, pengobatan, tindakan dan pelayanan lain yang telah diberikan kepada pasien. Salah satu isi dari berkas rekam medis yaitu diagnosis. Diagnosis adal ah identifikasi sifat-sifat penyakit atau kondisi atau membedakan satu penyakit atau kondisi dari yang lai nnya. Diagnosis ditegakkan oleh dokter atau dokter gigi yang memberikan pelayanan melal ui pemeriksaan fisik dan pemeriksaan penunjang lain yang dapat diklasifikasikan ke dalam sifat atau perangai suatu penyakit. Salah satu klasifikasinya adalah neoplasma.

Neoplasma adalah setiap pertumbuhan baru dan abnormal, khususnyaketikaterjadi multiplikasi sel yang tidakterkontrol dan progresif (Dorland, 2015). Kegiatan dan tindakan serta di agnosis yang ada di dal am rekam medis harus di beri kodedan selanjutnya di indeks agar memudahkan pelayanan pada penyajian informasi untuk menunjang fungsi perencanaan, manajemen, dan riset bidang kesehatan. Pemberian kode ini mengacu pada International Classification of Disease and Related Health Problem 10 ${ }^{\text {th }}$ Revision (ICD 10) untuk diagnosis dan International Classification of Disease, $9^{\text {th }}$ Revision Clinical Modification (ICD 9 CM) untuk 
Any Octavia Purnama Sari dan Imas Masturoh. Gambaran Ketidaktersediaan Dokumen Rekam Medis ...

[Online]. Vol 3No 1 halaman 103-108. Tersedia : http://jmiki.aptirmik.or.id/index.php/jmiki/ article/view/76 [2] uni 2016].

Ardhitya, Tyas, et al (2015). Faktor-faktor yang melatarbelakangi penolakan klaim BPJ S oleh Verifikator BPJ S di RSUD Dr. Amino Gondohutomo Provinsi Jawa Tengah Tahun 2015. [Online]. Tersedia : http://eprints.dinus. ac.id/17385/1/jurnal_15985.pdf [11] uni 2016].

Astianto, Anggit, et al. (2014). Pengaruh StresKerja dan Beban Kerja Terhadap Kinerja Karyawan PDAM Surabaya. DalamJ umlallmu dan Riset Manajemen. Vol 3 No 7 hal aman 1-17.

BPJS Kesehatan. (2014). Petunjuk Teknis Verifikasi Klaim BPJ S Kesehatan. [Online]. Tersedia: http://www.bpjs-kesehatan.go.id [14 Februari 2016].

Budi, Savitri Citra. (2011). Manajemen Unit Kerja Rekam Medis. Yogyakarta: Quantum Sinergi Media.

Burnett, Susan, et al. (2011). Missing Clinical Informationin NHSHospital OutpatientClinics: Prevalence, Causeand Efeects on PatientCare. DalamBMC Heal th Senvices Research [Online]. Vol 11 hal aman 1-7. Tersedia: http://www.ncbi. nlmnih.gov/pmc/articles/PMC3118108/. [4 Februari 2016].

Hatta, Gemala. (2013). Pedoman Manaj emen Informasi Kesehatan disarana Pelayanan Kesehatan. Jakarta: Universitas Indonesia

Huffman Edna K. (1994). Heal th Information Management, Tenth Edition, Physicians' Record Company, Berwyn Illinois, AHIMA.

Indra(2015). Mengapa Orang Paling Ingat Hari Senin danJ umat. [Online]. Tersedia: httpo://www.feed. id/article/mengapa-orang-pal ing-ingat-harisenin-dan-jumat-150918j.html [2 Juni 2016].

Keputusan menteri kesehatan No. 81 tahun 2014 tentang Penyusunan Perencanaan Sumber Daya Manusia Kesehatan di Tingkat Provinsi, Kabupater/Kota serta Rumah Sakit

Komite Keselamatan Pasien Rumah Sakit. (2008). Pedoman Pelaporan Insiden Keselamatan Pasien (IKP). Jakarta: Persi

Malonda, Taliana, et al. (2015). Analisis Pengajuan Klaim Badan Penyelenggara J aminan Sosial (BPJ S) Kesehatan di RSUD Dr. SamRatulangi Tondano. DalamJ IKMU. Vol 5 No 2b halaman 436-447.

Nurmawati. (2010). Mutu Pelayanan Kebidanan. Jakarta: CV. Trans Info Media.
Peraturan Gubernur Daerah Istimewa Yogyakarta Nomor 25 Tahun 2009 tentang Standar Pelayanan Minimal Rumah Sakit

Peraturan Menteri Kesehatan Republik Indonesia Nomor.269/MENKES/PER/III/2008 tentang RekamM Medis.

Peraturan Menteri Kesehatan Republik Indonesia Nomor.27 tahun 2014 tentang Petunjuk Teknis Sistem Indonesian Case Base Groups (INACBG'S).

Pujihastuti, Antik, etal (2014). Hubungan Kelengkapan Informasi dengan Keakuratan Kode Diagnosis dan Tindakan pada Dokumen Rekam Medis RawatI nap. DalamJ umal ManajemenI nformasi Kesehatan Indonesia [Online]. Vol 3 No 1 hal aman 60-64. Tersedia: http://jmiki.aptirmik. or.id/index.php/jmiki/article/viewFile/25/11 [2 Juni 2016].

Ratnasari, Amik Novia, etal (2016). Sisteml nformasi Rekam Medis di Bagian Filing di Rumah Sakit UmumDaerah Dr. Moewardi. DalamJ urnal Manajemen Informasi Kesehatan Indonesia [Online]. Vol 4 No 1. Tersedia : http:/l jmiki.aptirmik.or.id/index.php/jmiki/article/ view/100 [2 J uni 2016].

Saryono, Ari Setiawan. (2011). Metodologi Penelitian Kebi danan DIII, DIV, S1 danS2. Yogyakarta: Nuha Medika

Schilling, Lisa, et al. (2010). Perceived Frequency and Impact of Missing I nformation at Pediatric Emergency and General Ambulatory Encounter. Dalam Applied Clinical Informatics. [Online]. Vol 1 No 3 halaman 318-330. Tersedia : http://www.ncbi.nlm.ni h.gov/pmc/articles/ PMC3631895/ [7 Maret 2016].

Sulistya, Indra Ayu (2015). Analisis Perkiraan Kebutuhan Tenaga Kerja Rekam Medis di TPPRJ dengan Metode WISN di Puskesmas Mojolabab Tahun 2013. Dalam Indonesian J ournal on Medical Science Vol 2 No 1 hal aman $1-6$.

Undang-Undang No. 36 tahun2009 tentang Kesehatan.

Undang-Undang No. 44 tahun 2009 tentang Rumah Sakit.

Wahyuni, Tri. (2015). Alasan IImiah Senin dan J umat Lebih Populer dari Hari Lainnya. [Online]. Tersedia: http://www.cnnindonesia.com/gayahidup/20150904073437-277-76576/al asanilmiah-senin-dan-jumat-lebih-populer-dari-harilainnyal [18 Februari 2016]. 